\title{
Thermo-Physical Properties of Kenaf-Filled Acrylonitrile Butadiene Styrene Composites
}

\author{
Siti Nikmatin ${ }^{1}$, Achmad Syafiuddin $^{2}$, Naresworo Nugroho ${ }^{3}$, Widya Utama ${ }^{2}$, Agus Sukarto Wismogroho ${ }^{4}$ \\ ${ }^{1}$ Department of Physics, Bogor Agricultural University, 16680 Bogor, Indonesia \\ ${ }^{2}$ Department of Geophysics Engineering, Sepuluh November Institute of Technology, 60111 Surabaya, Indonesia \\ ${ }^{3}$ Department of Forest Products Technology, Bogor Agricultural University, 16680 Bogor, Indonesia \\ ${ }^{4}$ Research Center for Physics, Indonesian Institute of Sciences, 15310 Serpong, Indonesia
}

\begin{abstract}
Studies on advantageous of natural fillers incorporated into polymer composites on thermo-physical and mechanical properties are still intensively investigated. Several evidences suggest that the natural fillers with small contents combined with polymer increase their composite properties. We thus investigate thermo-physical properties of kenaf-filled acrylonitrile butadiene styrene (ABS) composites. ABS with 5\% kenaf microparticle size (ABS/K5), ABS with 5\% kenaf short fiber (ABS/KSF5), and recycled ABS with 5\% kenaf microparticle size (RABS/K5) were manufactured. Granular composites were manufactured by the twin screw extruder. Composite properties in terms of $\mathrm{X}$-ray diffractions, surface morphologies, and thermal behaviors were investigated. The present work found that ABS/KSF5 has the highest degree of crystallinity compared to others. No significant difference was found in terms of thermal properties of the composites.
\end{abstract}

\section{Introduction}

The worldwide availability of natural resources and agrowastes is the potential to be used as alternative fillers in composites. The rapidly expanding use of composites in automotive and construction leads to develop new sustainable and renewable composites. In addition, the advantages in using natural fillers are low cost, low density, renewable, minimize the environmental pollution caused by the characteristic biodegradability, and may straightly increase socio-economy aspects [1-5]. Several studies reported that the composite materials combined with natural fibers or fillers improved their physical and mechanical properties [1, 6-9]. These improvements were associated with economic advantages, such as low production cost and low resin consumption, which are strongly considered in industrial aspects [10].

Many types of natural fillers, which are used to reinforce polymer composites, were manufactured and investigated [1, 2, 6]. Essabir et al. [1] reported that the reinforcement argan nut shell (ANS) with polypropylene improved intention and torsion of the composites. Essabir et al. [2] noticed that the thermal stability of clay reinforced into high density polyethylene was more thermally stable than the composites produced by high density polyethylene with the oil palm fibers. Alternatively, Nikmatin et al. [6] found that the rattan nanoparticle incorporated into polypropylene increased the thermal stability of the composite. Another reinforcement of natural fibers or fillers of plants or agro- wastes having lower density are essential to be investigated.

Furthermore, the present work aims to investigate thermo-physical properties of kenaf-filled acrylonitrile butadiene styrene composites. Kenaf fiber and kenaf with microparticle size were considered in the present study. This paper is then organized as follows. Materials of the composite are first described in section 2 . Then, the procedures for producing kenaf fiber and kenaf with microparticle size are described in detail in the same section. Examination of X-ray diffraction, morphological study, and thermal inspection are also described in section 2. Section 3 provides results and findings that are discussed in detail. This paper ends with section 4 providing conclusions and suggestions for future work.

\section{Materials and methods}

\subsection{Materials}

In this study, kenaf stalks (KS) were obtained from farmers under PT Global Agrotek Nusantara, Riau. The $\mathrm{KS}$ have about 5 to $6 \mathrm{~m}$ in height and 1.5 to $3 \mathrm{~cm}$ in diameter. For the matrix, we use original acrylonitrile butadiene styrene (Torray Toyulac Resin 100MPJ 40049689 NLG). For the comparison purpose, recycled ABS supplied by PT MUB Jaya was used. Maleic anhydride from Germany was used as coupling agent. Composition of composites is $5 \%$ kenaf (fiber or 
microparticle), 92\% ABS, and 1\% coupling agent for all the composites (see Table 1).

Table 1. Composition of composites

\begin{tabular}{|l|l|}
\hline Designation & Composition \\
\hline ABS/K5 & ABS with 5\% kenaf microparticle \\
\hline ABS/KSF5 & ABS with 5\% kenaf short fiber \\
\hline RABS/K5 & $\begin{array}{l}\text { Recycled ABS with 5\% kenaf } \\
\text { microparticle }\end{array}$ \\
\hline
\end{tabular}

\subsection{Preparation of fillers}

In order to obtain kenaf short fibers (KSF), KS were saturated for 7 days. Furthermore, the KS were dried under the sun to reduce $\mathrm{KS}$ water content. This is followed by drying process using oven at temperature of $60{ }^{\circ} \mathrm{C}$ until the $\mathrm{KS}$ have about $8 \%$ in water contents. $\mathrm{KSF}$ were fabricated using milling machine. It was performed at $25000 \mathrm{rpm}$ in milling speeds for 2 minutes. In order to obtain KSF that are uniform, obtained KSF from milling machine were then sieved with 20 mesh in sieving size. Kenaf microparticle were produced by milling machine with high energy (FOMEC MDY-1000g) using KSF after sieved. The machine was operated with $28000 \mathrm{rpm}$ in milling speeds for 10 minutes with a voltage of $220 \mathrm{~V}$ and a power of 2000 watt.

\subsection{Preparation of composites}

Granular composites were fabricated by the twin-screw extruder (Collin model). Extrusion process was used to produce composites from the combinations of kenaf (fiber or microparticle), ABS, and coupling agent. Type of extrusion applied in this study was direct extrusion. The materials were placed on the hoper machine and a force then is given through barrel using screw. The screw consists of feeding section, compression section, and metering section. The extrusion process was operated at temperature of $170{ }^{\circ} \mathrm{C}$.

\subsection{X-ray diffraction analysis}

X-ray diagram was recorded by Emma 013B model. It was operated at $35 \mathrm{kV}$ and $28 \mathrm{~mA}$. Radiation wavelength that was used in this study is $\mathrm{Cu} \mathrm{K} \alpha=1.540 \AA$ in the range $=10$ to $80^{\circ}$ with a step of $0.02^{\circ}$ at a scan rate of $2^{\circ}$ $\mathrm{min}^{-1}$. Weight of all samples that are used in this study is about $10 \mathrm{~g}$.

\subsection{Morphological study}

Surface morphology of composites was observed by means of Scanning Electron Microscopy (SEM) using JEOL model (JSM-6510LA). It was operated at an accelerating voltage of $20 \mathrm{kV}$. In order to prevent electrostatic charging and low image resolution during examinations, sputter coated with gold was applied in this examination.

\subsection{Thermal inspection}

Thermal analysis was carried out by means differential scanning calorimeter (DSC) using JADE model, USA. It was operated in temperature ranges of 30 to $450{ }^{\circ} \mathrm{C}$ under nitrogen rate of $20 \mathrm{cc} \mathrm{min}{ }^{-1}$ using scan rate of $20^{\circ} \mathrm{min}^{-1}$. Weight of all the samples that are used in the current study is about $4 \mathrm{mg}$.

\section{Results and discussion}

\subsection{X-ray diffraction analysis}

$\mathrm{X}$-ray diffraction is one of material examination that is used to identify structure and crystal sizes of materials. Figure 1 shows the X-ray diffraction patterns of ABS with various fillers. Kenaf fiber used in this study has monoclinic structure with $a=7.87, b=10.31$, and $c=$ 10.31; and $\alpha=\gamma=90^{\circ}$ and $\beta=122^{\circ}$. It has the highest peak of $2 \theta=22.48^{\circ}$ JCPDS. In addition, ABS has consists of phase of polyacrylonitrile $((\mathrm{C} 3 \mathrm{H} 3 \mathrm{~N}) n)$, butadiene (C4H6), and polystyrene ((C8H8)n) with dominant phase is polystyrene. It has structure of cubic crystal with $a=b=c=21.95$ and $\alpha=\beta=\gamma=90^{\circ}$ with the highest peak of $2 \theta=21.5^{\circ}$.

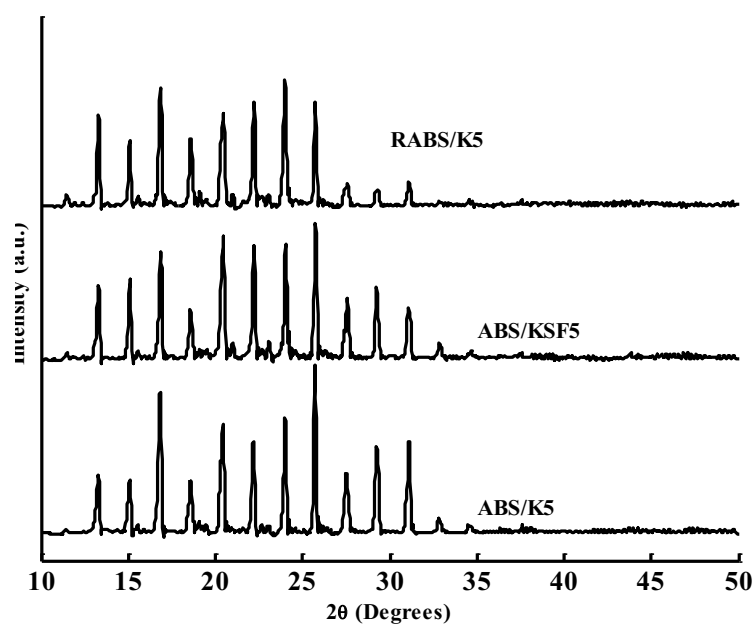

Figure 1. X-ray diffractograms of ABS with various fillers.

Biocomposites investigated in the present study consists of monoclinic and cubic structure. $\mathrm{ABS} / \mathrm{K} 5$ and $\mathrm{ABS} / \mathrm{KSF} 5$ have two highest peaks of $2 \theta=16.8$ and $2 \theta$ $=25.7$. Interestingly, RABS $/ \mathrm{K} 5$ has the highest peak of $2 \theta$ $=16.8$ and $2 \theta=24$. Slightly difference in the second peak may be due to by polymer used in RABS/K5 was from recycled ABS. This is an interesting subject research for future investigating in terms of physical, chemical, and mechanical properties of the composites. Another important finding that was found in this study was that ABS/KSF5 has the highest degree of crystallinity compared to others. The present study found that $\mathrm{ABS} / \mathrm{K} 5, \mathrm{ABS} / \mathrm{KSF} 5$, and $\mathrm{RABS} / \mathrm{K} 5$ have degree of crystallinity of $57 \%, 68 \%$, and $65 \%$, respectively.

3.2 Morphological properties 
Observed morphology in scanning electron microscopy (SEM) is formed by using electrons beam. Surface material used must be conductive in order to the electron can be reflected from the surface material. Figures 2(a) 2(c) show the surface morphology of ABS/K5, $\mathrm{ABS} / \mathrm{KSF} 5$, and RABS/K5, respectively. We can see that ABS/KSF5 exhibits better interaction between filler and polymer. It is clear that $\mathrm{ABS} / \mathrm{KSF} 5$ has the highest degree of crystallinity compared to $\mathrm{ABS} / \mathrm{K} 5$ and $\mathrm{RABS} / \mathrm{K} 5$. Otherwise, surface morphology of ABS/K5 and $\mathrm{RABS} / \mathrm{K} 5$ shown that the distribution of kenaf microparticles concentrated in certain part of the composites. These patterns were known a phenomenon defined as agglomeration [11]. These findings suggest for future manufacturing composites using kenaf microparticle incorporated into $\mathrm{ABS}$ polymer have to vary another pressure and temperature in TSE machine. These variables used in this study may be appropriate for kenaf short fiber. As discussed, ABS with kenaf short fiber has the highest degree of crystallinity.
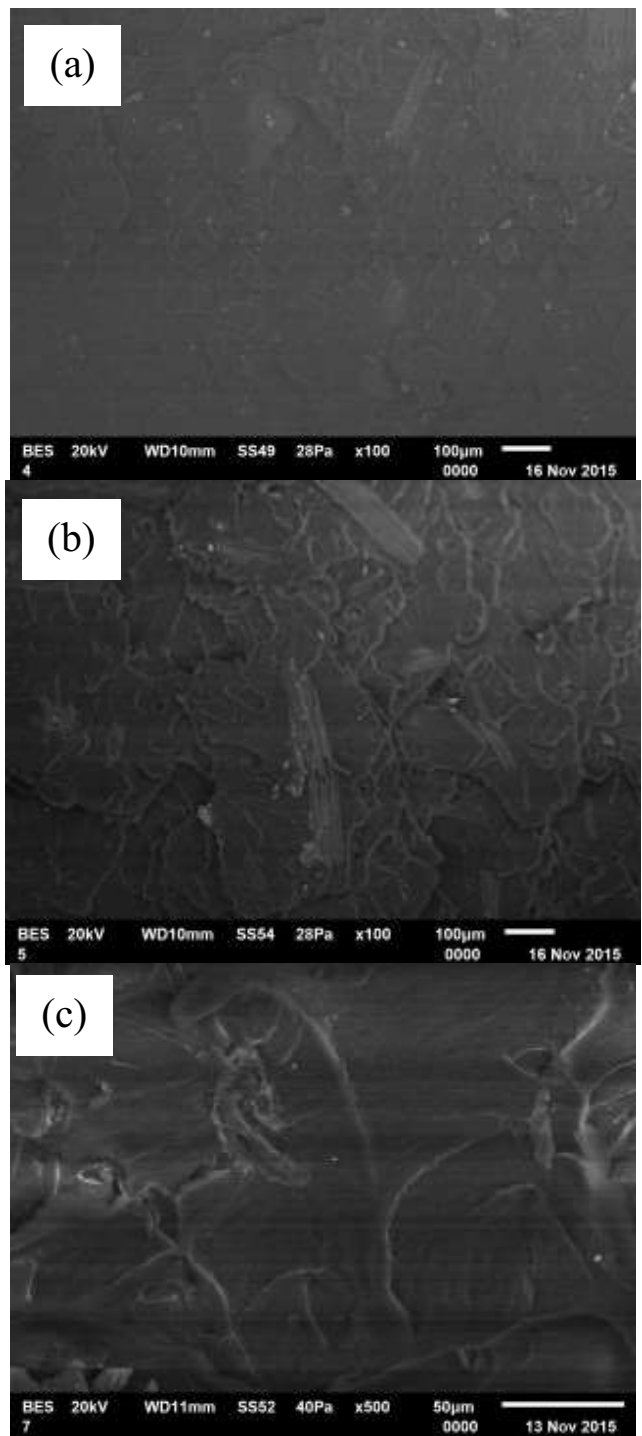

Figure 2. Scanning electron microscopy of (a) ABS/K5, (b) $\mathrm{ABS} / \mathrm{KSF} 5$, and (c) RABS/K5.

\subsection{Thermal properties}

Figures 3(a) - 3(c) show the thermal behaviors of $\mathrm{ABS} / \mathrm{K} 5$, ABS/KSF5, and RABS/K5, respectively. This study found that $\mathrm{ABS} / \mathrm{K} 5$ has the onset temperature $\left(T_{\text {onset }}\right)$ at $426.45{ }^{\circ} \mathrm{C}$ and the end temperature $\left(T_{\text {end }}\right)$ at $443.08{ }^{\circ} \mathrm{C}$. In addition, ABS/KSF5 has $T_{\text {onset }}$ at $427.09{ }^{\circ} \mathrm{C}$ and $T_{\text {end }}$ at $443.09{ }^{\circ} \mathrm{C}$ and $\mathrm{RABS} / \mathrm{K} 5$ has $T_{\text {onset }}$ at $428.63{ }^{\circ} \mathrm{C}$ and $T_{\text {end }}$ $442.95{ }^{\circ} \mathrm{C}$. Qiu et al. [12] reported that $T_{\text {onset }}$ of composites increases with the rise cellulose content from 0 to $60 \%$. In this study, no significant difference was found in $T_{\text {onset }}$ and $T_{\text {end }}$ of all composites.
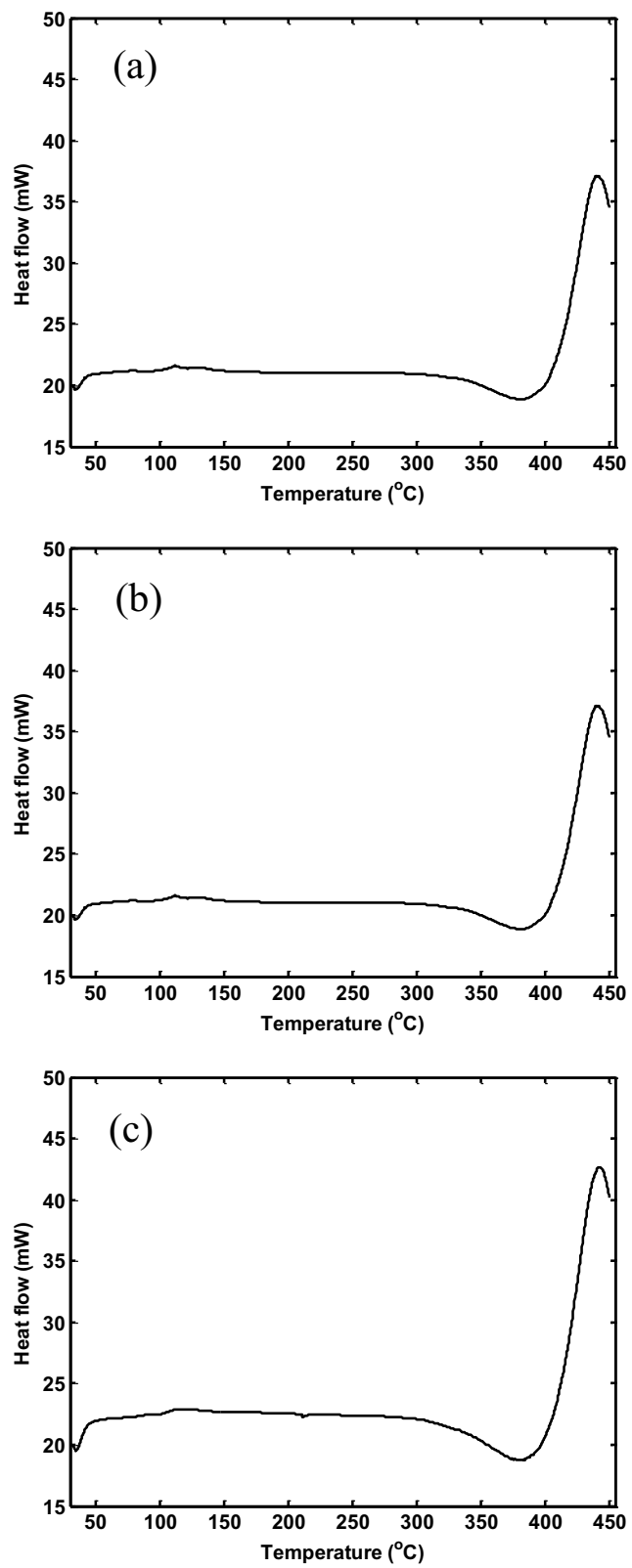

Figure 3. Thermal properties of (a) ABS/K5, (b) ABS/KSF5, and (c) RABS/K5.

\section{Conclusion}

The present work investigated thermo-physical properties of kenaf-filled acrylonitrile butadiene styrene composites. It was found that $\mathrm{ABS} / \mathrm{KSF} 5$ has the highest degree of crystallinity compared to RABS/K5 and ABS/K5. These finding were confirmed by the surface morphology of all composites. This study found that the thermal properties 
of all composites were not significant difference. In general, therefore, it seems that the natural filler used in this study is the potential to be exploited as alternative filler in order to produce a biocomposite materials that can be used as helmet materials, which are parts of our ongoing investigation. The present study makes several noteworthy contributions to materials science especially in exploring recycled matrix and fillers obtained from natural resources. A limitation of this study is that there is no variation in filler contents for recycled or virgin matrix. Further experimental investigations are essentially needed to investigate the composites properties with many variations in filler contents.

\section{References}

1. H. Essabir, M.O. Bensalah, D. Rodrigue, R. Bouhfid, A.E.K. Qaiss, Carbohydr. Polym. 143, (2016)

2. H. Essabir, R. Boujmal, M.O. Bensalah, D. Rodrigue, R. Bouhfid, A.E.K. Qaiss, Mech. Mater. 98, (2016)
3. I. Naghmouchi, F.X. Espinach, P. Mutjé, S. Boufi, Mater. Des. 65, (2015)

4. H.M. Akil, M.F. Omar, A.A.M. Mazuki, S. Safiee, Z.A.M. Ishak, A. Abu Bakar, Mater. Des. 32, 8-9 (2011)

5. D.B Dittenber, H.V.S. GangaRao, Composites, Part A 43, 8 (2012)

6. S.Nikmatin, A. Syafiuddin, A.B.H. Kueh, Y.A. Purwanto, Jurnal Teknologi 77, 16 (2015)

7. Y. Ruksakulpiwat, J. Sridee, N. Suppakarn,W. Sutapun, Composites, Part B 40, 7 (2009)

8. S. chi, Mech. Mater. 40, 4-5 (2008)

9. M.S Jamil, I. Ahmad, I. Abdullah, J. Polym. Res. 13, 4 (2006)

10. S.H. Aziz, M.P. Ansell, Compos. Sci. Technol. 64, 9 (2004)

11. M. Inkyo, T. Tahara, T. Iwaki, F. Iskandar, C.J. Hogan Jr, K. Okuyama, J. Colloid Interface Sci. 304, 2 (2006)

12. W. iu, F. Zhang, T. Endo, T. Hirotsu, J. Appl. Polym. Sci. 87, 2 (2003) 